\title{
It's in 3D, but is it truly the next dimension?
}

\author{
Jonathan M. Chen, MD
}

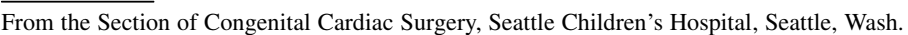 \\ Disclosures: Author has nothing to disclose with regard to commercial support. \\ Received for publication Oct 24, 2016; accepted for publication Oct 27, 2016; available ahead of print Dec 16, \\ 2016. \\ Address for reprints: Jonathan M. Chen, MD, Section of Congenital Cardiac Surgery, Seattle Children's Hospital, \\ 4800 Sand Point Way, NE, Seattle, WA 98105 (E-mail: jmchen@uw.edu). \\ J Thorac Cardiovasc Surg 2017; 153:923 \\ 0022-5223/\$36.00 \\ Copyright (C) 2016 Published by Elsevier Inc. on behalf of The American Association for Thoracic Surgery \\ http://dx.doi.org/10.1016/j.jtcvs.2016.10.046
}

Since the first description of a tissue-engineered blood vessel substitute by Weinberg and Bell in 1986, ${ }^{1}$ there has been a spirited search for the holy grail of durable tissueengineered vascular grafts (TEVGs) as alternative conduits for congenital heart surgery. Innumerable innovative and compelling designs have been suggested-degradable and partially degradable platforms, stem cell-based scaffolds, and tissue engineering across in vitro, in vivo, and in situ domains. Yet, none has achieved the ideal profile, which is outstanding mechanical properties, biological compatibility, low thrombogenicity, exceptional biodegradation kinetics, ready availability, and personalized production to account for patient anatomic variability. ${ }^{2}$

Fukunishi and colleagues ${ }^{3}$ present early results of 3dimensional (3D) nanofiber TEVGs in a sheep model with inferior vena cava (IVC) interposition grafts. ${ }^{3}$ Ingenious in its cell-free simplicity, the study demonstrates very intriguing results at 6 months, with the suggestion of near complete degradation of the scaffold, evidence of smooth muscle cell ingrowth, essentially normal mechanical properties compared with the native IVC, and no evidence of thrombosis or stenosis at short-term follow-up.

Although the immediate logical correlate of this technology would be use as a total cavopulmonary connection alternative to polytetrafluoroethylene, in truth the need for a tube graft with growth potential in this clinical setting is relatively small. However, when one considers the next-order extrapolationnamely a personalized 3D printed graft that could, for example, incorporate the fantasy of more perfect fluid mechanics across a 2-limbed Y-graft to optimize pulmonary artery growth - the story becomes considerably more interesting. ${ }^{4}$

The ingrowth of an organized smooth muscle cell layer and evidence of endothelialization at 6-month evaluation is also novel, although whether this simply represents the early phases of a process that could presage later stenosis is unclear (in particular, in light of CD68+ cell deposition). Moreover, although these TEVGs demonstrated mechanics comparable to the native IVC, their most appealing use (eg, as right ventricle to pulmonary artery conduits) could be constrained by aneurysmal dilation and inadequate burst strength; indeed, this was the limitation in the original work by Weinberg and Bell. ${ }^{1}$

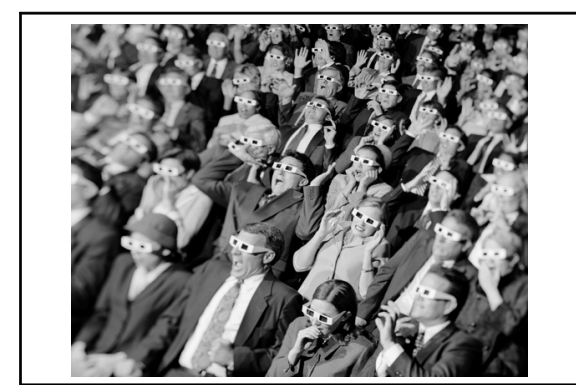

First-generation three-dimensional printed scaffolds pale in comparison to what will be expected of such grafts in vivo.

\section{Central Message}

Three-dimensional nanofiber tissue-engineered interposition grafts demonstrate very intriguing results at 6 months in a sheep model, but the challenges of clinical application are considerable.

See Article page 924.

Dissimilar to other technologies that have promulgated off-the-shelf availability as their appeal, the prospect of $3 \mathrm{D}$ printed grafts made for specific patient anatomy is particularly seductive in the congenital domain where anatomic variance is the norm. Yet, like early 3D movies compared with today's image maximum (IMAX) film format and projection standards (and by extension philosophically like IMAX compared with high-definition television or IMAX compared with real life), these firstgeneration 3D-printed scaffolds pale in comparison to what will be expected of such grafts in vivo: more complex anatomic constructs, durability in the setting of higher pressure systems, and native growth without luminal narrowing. The dream of the simulated third dimension is that it be so good that it seems real. Hopefully the results of this elegant study represent the first steps toward that dream.

\section{References}

1. Weinberg CB, Bell E. A blood vessel model constructed from collagen and cultured vascular cells. Science. 1986;231:397-400.

2. Li ZK, Wu ZS, Lu T, Yuan HY, Tang H, Tang ZJ, et al. Materials and surface modification for tissue engineered vascular scaffolds. J Biomater Sci Polym Ed. 2016; 27:1534-52.

3. Fukunishi T, Best CA, Sugiura T, Opfermann J, Ong CS, Shinoka T, et al. Preclinical study of patient-specific cell-free nanofiber tissue-engineered vascular grafts using 3-dimensional printing in a sheep model. J Thorac Cardiovasc Surg. 2017; 153:924-32.

4. Haggerty CM, Kanter KR, Restrepo M, de Zélicourt DA, Parks WJ, Rossignac J, et al. Simulating hemodynamics of the Fontan Y-graft based on patient-specific in vivo connections. J Thorac Cardiovasc Surg. 2013;145:663-70. 